\title{
Developing and evaluating a project management methodology (PMM) for university-industry collaborative projects
}

\author{
Christina Chin May Maya, Yap Eng Hwa ${ }^{b}$, Andrew Spowage ${ }^{b}$ \\ aKuala Lumpur Infrastructure University College \\ buniversity of Nottingham Malaysia Campus \\ e-mails: christinachin@kliuc.edu.my; EngHwa.Yap@nottingham.edu.my; Andrew.Spowage@nottingham.edu.my
}

\begin{abstract}
This study investigates the development of a project management methodology (PMM) to be adopted in a university-industry collaborative (UIC) research environment through semi-structured interviews with project leaders from both universities and industries. This paper presents the findings of a qualitative survey conducted with respondents from the universities and industries involved in collaborative R\&D projects in Malaysia. These findings together with those of previous works were used to design an appropriate PMM. The validity of the PMM was assessed by a panel of experts including recognized leaders in the field. The novelty of this survey research is in the creation of a PMM guidebook that offers guidance to the actors involved, assisting them to plan, manage and close their projects successfully.
\end{abstract}

Keywords: project management methodology, university-industry, collaborative research.

\section{Introduction}

The formation of university-industry collaborative (UIC) partnerships can be as simple as a hand-shake based upon a prior relationship to a complex negotiation involving issues of intellectual property (IP), licensing and protracted contractual agreements. The associated negotiations commonly result in conflict between the various actors. Yet substantial research suggests that discussion and subsequent agreement on such matters is essential to mitigate longer term issues, to maximize returns and to facilitate the development of a sustainable partnership.

It is important to determine common barriers to the formation and subsequent operation of UIC partnerships so that they can be managed and mitigated (KOECH, 1995). The primary barriers to the formation of UIC partnerships are associated with the vastly different cultures and motivations (AUGUSTINE; COOPER, 2009; SHERWOOD; BUTTS; KACAR, 2004) of the actors involved. From an operational perspective the distinction between operational environments and approaches of the different organizations (HARRIS, 2007) are commonly cited barriers. In another study, the most frequent obstacles encountered during both the formation and operation were attributed to the bureaucratic structures and processes which are unresponsive to the unique needs of upstream collaboration (MATTHEW; NORGAARD, 1984). Others commonly cited reasons are variable levels of commitment (HARRIS, 2007) and the inability to establish trust between partners (DAVENPORT;
DAVIES; GRIMES, 1999), a lack of insight into the importance of planning and management of the projects and poor partner selection (HOLMBERG; CUMMINGS, 2009, BUTLER; GILL, 2001; SHERWOOD; BUTTS; KACAR, 2004). The challenges which these factors created during both the formation and operation of UIC commonly lead to inter-organizational conflicts during the operational stage of the partnership and present significant challenges for all parties. It is therefore important to understand the techniques to mitigate the issues identified to improve the probability of managing a successful partnership in any methodology used to manage UIC.

To enhance the successful operation of UIC, Katz and Martin (1997) identified a need for formal management procedures, an attribute which does not come naturally to many academics. Gist and Langely (2007) further noted the importance of the application of an appropriate set of project management tools and techniques. It is a commonly held belief in the project management community that an appropriate project management methodology (PMM) offers significant benefits as a structured approach to the management of collaborative research projects. This notion is however, not without its critics, the majority of which comment that collaborative research should not follow or use any formalized methodology because it may hamper the flexibility, creativity, learning capacity, limit inter-personal connections and the general fit between the 
organizations (PHILBIN, 2008; KANTER, 1994). To date it should be noted that no PMM developed specifically for the management of UIC has been published; however it is common for university research offices and the appropriate departments within large companies to have a set of procedures for the management of projects. These procedures are often highly appropriate and may form the foundations of any PMM. The distinction between these procedures and a true PMM is one of rigor in the development, completeness and appropriateness for the task.

The aim of this paper is to develop a PMM which will guide academic researchers and industrial partners in the planning, management and operation of their partnership and help to mitigate the challenges associated while sustaining UIC partnerships. This paper presents the background research followed by an explanation of the research strategy and approach used to develop and evaluate the methodology presented. The paper ends with an overview of the completed PMM framework, with an outline of each module's key objectives, activities and outputs and final evaluation by expert panel and makes recommendations for further study.

\section{PMM as the key concept}

Across all industrial sectors, project management has become an essential element in the successful delivery of projects (CHARVAT, 2003; MUNNS; BJERMI, 1996; MILOSEVIC; PATANAKUL, 2005; PITAGORSKY, 2003; JOSLER; BURGER, 2005). Regardless of the industrial sector or size of project, a PMM can be applied to improve the probability of meeting project goals (CHARVAT, 2003; MILOSEVIC; PATANAKUL, 2005; PITAGORSKY, 2003).

By definition there can be no single generic PMM that can be universally applied to manage projects across all sectors nor all project within the same sector (COCKBURN, 2004; CHARVAT, 2003). A wide range of sector specific methodologies exist, however many are not fully developed and none meet the specific needs of UIC research projects (CHIN; SPOWAGE, 2010). Further, a number of studies have revealed that PMM are often underused, wrongly used, are unusable or simply oversold (CHARVAT, 2003; KAUTZ; PRIES-HEJE, 1999). Due to the demanding project environment, a PMM developed for the management of UIC projects that exhibits any of these characteristics would be destined for failure.

There is no universal agreement as to what constitutes a PMM. A PMM must be clear in what it covers; be simple to understand and apply and above all it should be useful (CHARVAT, 2003). It should provide standard methods and guidelines to ensure that projects are completed on time, within budget and are conducted in a disciplined, wellmanaged and consistent manner that serves to promote the delivery of quality results (JOSLER; BURGER, 2005). It is a road map to get you from where you are to where you want to be (MURCH, 2001) but definitely not merely a series of templates, forms and checklists although it will typically contain these (TURBIT, 2005). A PMM will identify specific approaches to managing each aspects of the project in the form of general and sector specific procedures, rules and regulations which sets the standards to ensure quality and control (JOSLER; BURGER, 2005; PITAGORSKY, 2003). A PMM also provides a means of identifying the risks and opportunities associated with the project. In its broadest sense, a PMM includes a wide range of knowledge areas and a set of tools and techniques for supporting and managing each aspect of the project (PITAGORSKY, 2003; MILOSEVIC; PATANAKUL, 2005).

Project methodologies need to function effectively for the full range of projects carried out within a specific project environment even when project characteristics such as team size, project criticality, nature and scope all vary widely (COCKBURN, 1999). Thus the methodology needs to be adaptable to project scale, for example as the project size grows larger, the scale and adaptation of the methodology will typically increase. In such cases it will typically be used to manage more resources and manpower, more tasks and larger budgets. As a consequence, the sophistication of the tools, techniques and processes employed will need to be similarly expanded. However, though with the significant increase in project scale, every project require the same level of transparency, accountability and traceability in documentation. In addition, the number of communication channels between team members, suppliers and stakeholders will be more complex as the project scale increases. Hence, a PMM must provide the project team with a set of processes which can be scaled or substituted as required on a project by project basis. By using a PMM, project teams will be able to clearly understand their scope of work, what each of them needs to accomplish, how their work fits in and contributes to the project as a whole and be provided with the appropriate tools and techniques to help them deliver their assigned tasks.

The application of a formalized PMM helps to clarify goals, identify the resources required and ensure accountability of results and performance (PROJECT MANAGEMENT FACT SHEET, 2004). By implementing a methodology, the likelihood of a project succeeding will be higher as well as the probability of delivering the project within scope, budget and on time. One of the best practices in facilitating the adoption of a PMM is to ensure that the methodology clearly defines roles and responsibilities, promotes open and direct channels of communication (CHARVAT, 2003) and allows those involved to immediately see the advantages to be gained through using a rigorously developed methodology. 
Many agreed that the use of a PMM increases the likelihood of project success. However, this condition only applies if the project manager understands the nature of the project and his ability to reshape the methodology to meet the specific needs of each project. It is of course impractical to develop a new methodology for each new project however; in the adoption and use of methodology it should be considered an easy task to customize the methodology to the project within a given environment (CHARVAT, 2003; COCKBURN, 1999; COCKBURN, 2000; CHEMMA; SHAHID, 2005). Significant efficiency advantages can be gained by facilitating multi-level customizing. The first level allowing customization of the methodology to the project environment and the pre-existing systems and practices of the organization involved, producing a project environment level methodology, analogues to an organization level PMM (CHIN; SPOWAGE, 2010). The second level of customization is then associated with minor modification to the project environment level PMM to make it suitable to manage a specific project. It is also important that the PMM is adaptable to the dynamic nature of projects, a factor endemic to research projects and to the changing stakeholder requirements.

Based on the above discussion and previous works (CHIN; SPOWAGE, 2010; CHIN; YAP; SPOWAGE, 2010), PMM can be defined as a comprehensive set of best practices, tools and techniques that are dynamic, flexible, adaptive and customizable to different projects within a specific environment. The methodology should therefore consist of a set of processes, templates, techniques and tools to assist in planning and managing the project throughout its entire life cycle. The components of the methodology will cover 1) project management processes such as initiating, planning, executing and monitoring project progress with 2) a selection of tools and techniques to communicate the delivery to the satisfaction of all stakeholders; 3 ) consolidated and integrated set of appropriate best practices and values of project management and 4) a list of references of terminology as a common denominator and language in the project environment.

\section{PMM in UIC research environment}

Project management today is a well-recognized discipline and has been widely practiced in numerous organizations. Further, many researchers agree that the adoption of PMM standards, technical procedures, tools and techniques for planning, controlling and implementation is the key to managing projects effectively (REGO; CARVALHO, 1995; SHENHAR, 1999; MULDER, 1997; GUO; CHEN; ZHOU, 2007; COOMBS; McMEEKIN; PYBUS, 1998; HULJENIC; DESIC; MATJASEVIC, 2005). The management of research projects in general is different from industrial projects and purely academic projects. As shown in Table 1, research projects are rather complicated. In a research project, participants such as researchers, academician, and doctoral students may not be able to commit $100 \%$ of their time to the project as they are committed to other work such as teaching and administration. Industrial projects are typically divided into tasks and sub-tasks however academic research projects tasks are frequently non-sequential and overlapping. Directions may change dramatically based on the results developed internally or externally (from the researcher's perspective) or strongly influenced by changes in the market conditions (from the industries' perspective); this is particularly true for project associated with leading edge product line. These factors combined with the uncertainties associated with research works dictate that the PMM must be both more able to cope with change and that the risk progresses employed in the management UIC projects must be an essential component.

Accepting the fact that uncertainty is an inevitable aspect in collaborative research projects. Different project management approaches are required and these need to be tailored for different types of projects (SHENHAR, 1999; COOMBS; McMEEKIN; PYBUS, 1998). As a result, the use of a specific project management tool or technique may not always be appropriate (LLYOD; SIMPSON, 2005). Therefore generating one generic model with a rigidly comprehensive set of prescribed tools and techniques to manage all projects would lead to unwieldy which would simply be too complex to function effectively. Therefore compromising and balancing a 'one-best-methodology' should be tailored for each unique project. UIC research projects can only be successful if both partners are willing to learn continuously through continuous adjustment and adaptations as well as continuous organization learning (HULJENIC; DESIC; MATJASEVIC, 2005; WECK, 2006).

\section{Research strategy and method}

The exploratory case study method was selected as the research approach. In this work, the context of the research is limited to UIC project environment in Malaysia and the development of a suitable PMM to manage UIC research projects. The boundaries of the work were defined to ensure that statistically representative data of the population could be collected within the constraints of this investigation. Although many of the finding will be applicable to UIC projects in other countries, prior to implementation the findings in this work should be tested against the specific national context. The case study approach was selected because it allows an in-depth investigation of the UIC as a relatively new phenomenon in Malaysia which has only recently being explored by a handful of Malaysian researchers (YEE; CHONG; ABAS, 2009a; ASLAN, 2006). The literature findings discussed above including the barriers 
Table 1. Industrial project management vs. academic research management.

\begin{tabular}{|c|c|}
\hline Industrial project management environment & Academic research environment \\
\hline Divide project into distinct project phases, tasks and sub-tasks & Phases and tasks in research overlap and are non-linear \\
\hline Projects are repetitive & Research projects are particular, singular and unique \\
\hline Projects are intra-organizational & Research projects are often inter-organizational \\
\hline Project participant work (almost) full time on the project & $\begin{array}{l}\text { Most researchers have other competing and possibly conflicting } \\
\text { obligations in their time e.g. teaching, administration or other } \\
\text { projects }\end{array}$ \\
\hline Plan and control (rationality) & $\begin{array}{l}\text { Planning and control is rather difficult (bounded rationality). } \\
\text { Uncertainty is high and project participants have high degree of } \\
\text { autonomy. Furthermore, too rigid control may be counter productive }\end{array}$ \\
\hline $\begin{array}{l}\text { Project manager generally knows what to do and gives professional } \\
\text { advice and instructions concerning the concrete work }\end{array}$ & $\begin{array}{l}\text { Research project manager has general but often lacks specific } \\
\text { knowledge in the research area. Instead the project participants are } \\
\text { those who know }\end{array}$ \\
\hline Goals have a commercial and/or applied technology orientation & $\begin{array}{l}\text { Goals may be abstract and/or subject to change. Goals may have } \\
\text { either non-commercial/ commercial or applied technology/non- } \\
\text { applied technology orientation }\end{array}$ \\
\hline $\begin{array}{l}\text { There is a customer relation or a clear impression of end user of the } \\
\text { result }\end{array}$ & $\begin{array}{l}\text { There may not be a "customer" other than researchers' peers and the } \\
\text { perspective of a potential end-user may be vague }\end{array}$ \\
\hline Limit uncertainty, safety first & $\begin{array}{l}\text { Uncertainty is inherent to research and innovative research must } \\
\text { take risks }\end{array}$ \\
\hline $\begin{array}{l}\text { Management (plan and control; emphasis on the procedure and } \\
\text { administrator management role) }\end{array}$ & $\begin{array}{l}\text { Leadership (innovation and integration; emphasis on the } \\
\text { entrepreneur and integrator management roles) }\end{array}$ \\
\hline $\begin{array}{l}\text { Evaluation: the purpose is to efficiently reach planned results (plan } \\
\text { and control) }\end{array}$ & $\begin{array}{l}\text { Evaluation: the purpose is to learn and reach the best achievable } \\
\text { result. Pre-planned result may prove second-best if set too low or } \\
\text { unrealistic if set too high }\end{array}$ \\
\hline
\end{tabular}

Source:(ERNO-KJOLHEDE, 2000; HULJENIC; DESIC; MATJASEVIC, 2005).

and challenges faced, best practices applied, requirements placed on a methodology and the relationship between the collaboration and project management processes were compiled and the validity and appropriateness to the current context tested. The results from this investigation are used to define a PMM appropriate for use in UIC projects; this PMM is then evaluated by an expert panel review. The final phase of this work outlines the final PMM developed. Further details on the phases of this research work and the key findings are described below.

\subsection{Phase 1: investigating the requirements and components of the PMM suitable for UIC research environment}

Interviews were carried out with university and industrial partners and the majority of interviews were carried out on a face to face basis with two interviews being conducted via the Skype video conferencing application. The average duration of the interviews was kept to 50 minutes to accommodate the respondent's tight schedules (see Table 2). Each of the interviewees in the sample group were involved or had been involved in UIC R\&D projects, taking the role of a project leader or lead researcher in the collaborative projects while each industrial interviewee were or had recently been a collaborative partner. All interviews were carried out using a semi-structured format with audiorecording which was transcribed directly after the interview to generate a written interview report. These reports were sent to the respondents for validation. Interview questions were generated based upon research questions, categorized and coded for questioning purpose (refer Appendix 1). As well as conducting interviews, respondents also participated in a questionnaire given at the end of the session that was self-administered to validate the factors and issues identified that were common in the UIC project environment. The organization types selected for the interview represent a diverse range of UICs that meets the research objectives:

- A foreign based university established in the market for 10 years that is keen to promote and establish more partnerships with industry.

- A research focused university that was the first university in the nation to be ranked above 200 worldwide (THE, 2009).

- A number of research focused universities recently established from the year 2000 that are still in the infancy stage of generating UIC projects.

- A university established in 1960 s, which was the first educational institution in the nation to be selected and given the Accelerated Program for Excellence (APEX) status. The university has been 
Table 2. Sample description of interviewed respondents.

\begin{tabular}{|c|c|c|c|c|c|}
\hline No & Respondent ID & Organization type & Date & Method & Duration (minutes) \\
\hline 1 & $\mathrm{U} 1$ & Foreign university & $02 / 9 / 09$ & FTF & 60 \\
\hline 2 & $\mathrm{U} 2$ & Research focused university & $11 / 9 / 09$ & FTF & 60 \\
\hline 3 & $\mathrm{U} 3$ & Focused university & $14 / 9 / 09$ & FTF & 40 \\
\hline 4 & U4 & Apex university & $26 / 10 / 09$ & TEL & 64 \\
\hline 5 & U5 & Comprehensive university & $12 / 11 / 09$ & FTF & 60 \\
\hline 6 & U6 & Comprehensive university & $7 / 10 / 09$ & TEL & 31 \\
\hline 7 & U7 & Research focused university & $22 / 10 / 09$ & FTF & 52 \\
\hline 8 & U8 & Comprehensive university & $27 / 10 / 09$ & FTF & 50 \\
\hline 9 & U9 & Focused university & $17 / 10 / 09$ & FTF & 50 \\
\hline 10 & U10 & Focused university & 9/10/09 & FTF & 52 \\
\hline 11 & U11 & Research focused university & 29/10/09 & FTF & 35 \\
\hline 12 & $\mathrm{I} 1$ & SME & $14 / 9 / 09$ & FTF & 60 \\
\hline 13 & $\mathrm{I} 2$ & SME & $24 / 9 / 09$ & FTF & 55 \\
\hline 14 & I3 & SME & $21 / 10 / 09$ & FTF & 50 \\
\hline 15 & I4 & SME & $13 / 11 / 09$ & FTF & 34 \\
\hline 16 & I5 & SME & $22 / 10 / 09$ & TEL & 20 \\
\hline 17 & I6 & SME & $30 / 10 / 09$ & FTF & 60 \\
\hline 18 & E1 & Research agency & $21 / 9 / 09$ & FTF & 45 \\
\hline 19 & E2 & University spin-off & $16 / 11 / 09$ & FTF & 66 \\
\hline \multicolumn{5}{|c|}{ Total duration } & 944 \\
\hline
\end{tabular}

Notes: University (U); Industry (I), External research agencies (E); Small Medium Enterprise (SME); Face to Face (FTF); Telephone (TEL).

in continuous partnership with government linked companies (GLC).

- A number of comprehensive universities established in the 1980s and 1990s whom are interested to establish a UIC centre of excellence, yet lack the experiences and skills but are collaborating extensively with industrial partners through their own efforts.

- The external respondent was an ex-chairman for the Centre for the National Resource \& Research Collaboration.

- A spin off company from a research focused university, aiding the university from consultation services to commercialization of innovated products.

- A small medium enterprise involved in providing integrated engineering expertise and businesses in project management, project resources, IT, consultancy and other services.

- An environmental biotechnology company with Bio-nexus status which had been in operation since the 1980's and is in collaboration with one of the research focused universities.

- A consulting engineering company experienced in structural, engineering and design that specializes in buildings for the defense sector and has been in partnership with a focused university for the past 2 years.
- A concrete based construction company in a successful collaboration with the focused university for over 2 years.

\subsection{Phase 2: evaluating the PMM through expert panel review model}

In this research, formative evaluation (van TIEM; MOSELEY; DESSINGER, 2004; SCRIVEN, 1996, MORRISON; KEMP; ROSS, 2001) and expert panel reviews (EVALSED, 2009) are utilized. The main objective is to focus attention on the importance of the strengths available and convert any weaknesses into strength. This involves gathering feedback from users and other relevant groups and using it for the development and implementation process. A questionnaire was chosen as the appropriate method of collecting quantitative data for the evaluation model selected. The objective of the questionnaire was to evaluate the developed PMM in order to seek expert panel judgment and suggestions for further improvements. The purpose of the expert panel evaluation is aimed at measuring the following elements (ADESOLA; BAINES, 2005, PLATTS, 1990):

- Feasibility; could the methodology be easily followed?

- Usability; is the methodology workable? Are the steps, tools and techniques easy to use and apply?

- Usefulness; is the methodology worth following? 
Will the methodology helps researchers to produce better results in project management?

- To identify areas of improvement for the methodology.

The questionnaire was designed based upon the understanding of the questions to be addressed in the study as well as the three assessment criteria to be evaluated by experts. The designed questions in each section of the expert panel review are shown in Appendix 2.

A pilot evaluation was carried out to assess the reliability of the questions designed in the evaluation form. Questions that were vague and ambiguous to evaluators were identified and restructured. The pilot evaluations were conducted with university researchers from the sample group to validate the questions. The selected evaluators included university academicians whom are or have been involved in UIC projects as the project leader or researchers; research agency; industrial members and project management experts (see Table 3). A total of 13 evaluators participated in the evaluation process that are distinct with varied background, organization, experiences, specialization and countries of origin, however the majority of them had:

- been handling projects for 11-20 years (35.7\%),

- handled more than 5 projects (42.9\%),

- previously taken course/training on project management $(57.1 \%)$,

- not used such methodology before (50\%).

The evaluation questionnaire was then distributed via email to all respondents. Prior briefing was given to each evaluator on the objectives and instructions on how to carry out the evaluation process. To encourage a better response rate, reminders were sent at appropriate times.

\subsection{Phase: 3 development of the pilot PMM}

The foundation of the PMM is based on the work completed in Phase 1, shown in Figure 1 and by leveraging on previous work which used similar methods to develop PMM for the management of project in the undergraduate (CHIN; SPOWAGE, 2008) and doctoral research environments (CHIN et al., 2011), an appropriate PMM was developed as outlined in Figure 1.

Upon determining the list of requirements for the PMM development, the study followed with an investigation to understand the growth and need of UIC in the literature and specifically in the Malaysian research environment. The key elements from this investigation were the challenges anticipated in UIC, best practices to ensure successful UIC partnerships and the process involved in UIC development, all of which were integrated into the structure of the PMM. The findings were used to design the questions for the semi-structure interview and questionnaire which were used to validate the PMM. Several themes and lists of essential element that needed to be integrated into the PMM were identified. These included:

- To develop a shared mission statement, vision and goals for the mutual benefit of both partners;

- The importance of recruiting and selecting a high caliber project manager from each partner to oversee the planning and monitoring of the project;

- The need for a standard list of regulations and guidelines to be placed in the PMM;

- The importance of risk management to mitigate and respond to risks;

- To create a communication plan to building more effective communication channels between partners;

- To facilitate separation of responsibilities between the technical and management aspects of the project to enhance productivity and delegation of work;

- To contain an integrated team commitment which is well understood by every team member during the initiation process of the project to ensure accurate activity planning and team commitment is achieved;

Table 3. PMM evaluation sample respondents.

\begin{tabular}{|c|c|c|c|}
\hline No & Respondent ID & Organization type & Evaluation date \\
\hline 1 & U1 & Foreign university & $6 / 8 / 10$ \\
\hline 2 & U2 & Foreign university & $12 / 8 / 10$ \\
\hline 3 & U3 & Foreign university & $23 / 8 / 10$ \\
\hline 4 & U4 & Focused university & $27 / 7 / 10$ \\
\hline 5 & U5 & Foreign university & $27 / 7 / 10$ \\
\hline 6 & U6 & Frivate university & $26 / 8 / 10$ \\
\hline 7 & U7 & Apex university & $14 / 9 / 10$ \\
\hline 8 & U8 & Research agency & $16 / 8 / 10$ \\
\hline 9 & E1 & Project management & $26 / 8 / 10$ \\
\hline 10 & I1 & Project management & $29 / 7 / 10$ \\
\hline 11 & PME1 & Project management & $16 / 8 / 10$ \\
\hline 12 & PME2 & PME3 & $27 / 8 / 10$ \\
\hline 13 & & Consultancy for Teaching \& Learning Organization & \\
\hline
\end{tabular}

Notes: University (U); External research agencies (E); Industry (I); Project Management Expert (PME). 


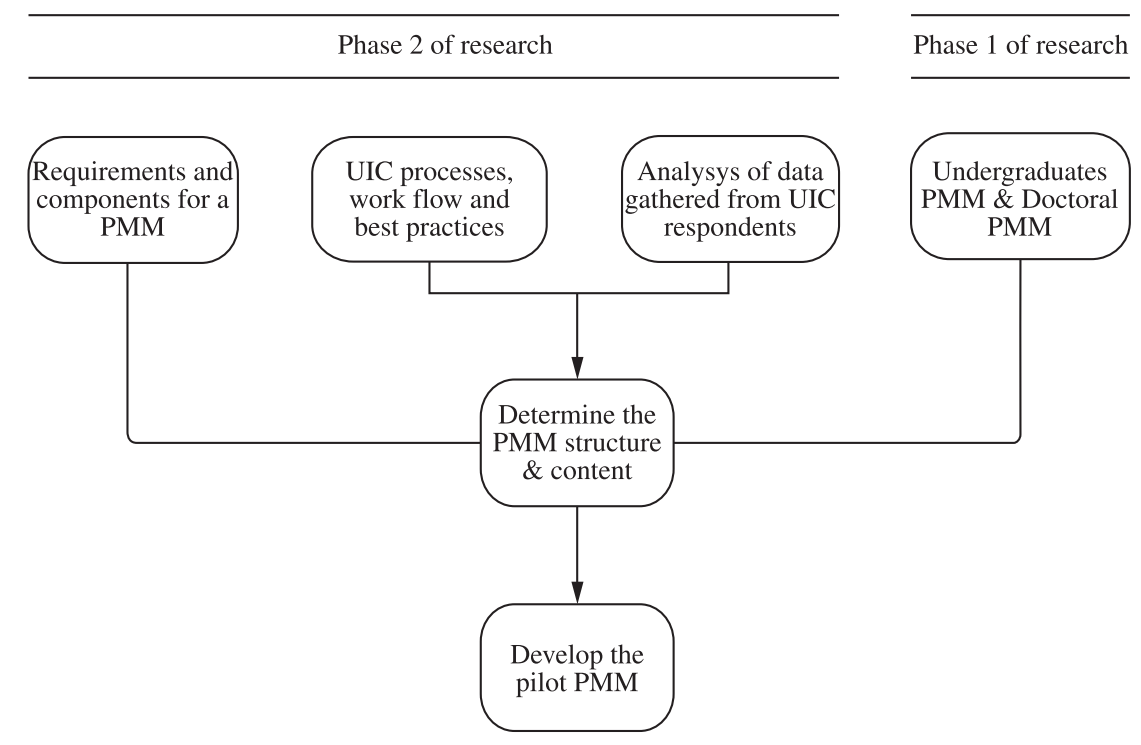

Figure 1. Development of the pilot PMM.

- To create a structured process of partner selection in the initiation process;

- To provide references and samples of collaboration agreements extracted from Lambert collaboration agreement model for use in establishing the UIC;

- To include information in sourcing external funds from funding bodies such as government to support and aid UIC R\&D costs and to integrate the management of funding bodies in the PMM e.g. with the use of communication plan etc;

- The identify the arrangement of partners under different situations with different forms of cooperation in UIC initialization;

- To establish an advisory board to oversee the structure of the collaboration; to evaluates, monitor and approve the key decisions related to project activities;

- The following components suggested by respondents should also be included in the PMM; relationship management, partner matching, project planning, contract management and ethical guidelines;

- To foster and maintain a sustainable long term relationships;

- To establish a framework to measure the value of the collaboration e.g. commercial value, knowledge management, technology transfer etc.

In the design of the pilot PMM guidebook, the structure of the guidebook consists of four parts namely:

Part A - introduction sets out the general concepts of a PMM, outlines who should be using this guidebook, why the adoption of this PMM is beneficial and its structure. It is an easy step by step guide which provides details of each module objectives, activities, inputs, outputs and toolkits. With the given guidelines in the PMM, it will assist those involved in UIC research projects. It is also intended for research management office (or equivalent) of university and industry to use this guidebook to design their own organization specific PMM (aligned with their own internal systems) to help them work more effectively on UIC research projects.

Part B - UNMC PMM introduces the modules of the methodology, objectives, inputs, tasks, relevant tools and techniques, outputs and hints and tips to guide throughout the process of setting up, planning and running a project. The PMM guidebook is an easy step by step guide which provides details of WHEN to do it? WHO will be involved? WHAT is it? and HOW to do it? It is also aligned with international best practice; therefore it integrates easily with the other systems within the organization.

Part $\mathbf{C}$ - toolkits provide a set of library sample tools and templates designed to reduce the administrative burden of effectively managing projects. It contains 32 sets of toolkits enclosed with simplified templates, hints and tips to give guidance especially to first time UIC researchers. Each tool and template is structured in the following way: what it is, what is its purpose, how to do it, hints and tips and samples to simplify the tool as much as possible. The PMM guidebook does not aim to be an answer book. It adopts a flexible structure enabling both university and industry players to customize the available approaches, tools and templates and makes them readily assessable in the guidebook to fit the project size, complexity, objectives and requirements. 
Part D - terms \& definitions contains a set of terms and abbreviations used within the methodology to ensure a common language between team members.

\section{Evaluation for improvement}

From the expert panel evaluation, a number of areas for minor changes were suggested by the respondents as shown in Table 4. Areas suggested for further improvement include idea conception, internal proposition, selection and evaluation of partner; identify core competencies, schedule planning and risk planning activities. New areas were also suggested by expert such as to create an issue management section to manage possible issues with a view of preventing them from becoming risks, to identify the key personnel involved in each task, to emphasize the importance of expert review as an individual toolkit for managing UIC projects and finally to automate the PMM guidebook as a web enabled application for greater usability. The suggested changes for the pilot PMM were used to refine and improve it for use and are repeated in the final version of the PMM.

Throughout the pilot evaluation, several observations and comments were also highlighted by respondents. Each of these comments was categorized based on the three criteria used to evaluate the pilot PMM is shown in Table 5.

Table 4. Areas for improvements identified via pilot PMM evaluation.

\begin{tabular}{|c|c|}
\hline Component & Areas for improvement \\
\hline Idea conception & - To include a task to prioritize ideas generated before probing the idea further in Module 1 \\
\hline Internal proposition & - The task 'identify stakeholders' should be completed in parallel with the project initiation document; \\
\hline Select and evaluate partner & $\begin{array}{l}\text { - More details on the evaluation of partners and negotiation process; } \\
\text { - The } 7 \text { C partner selection model should include some flexibility for different importance/priority weights } \\
\text { and to leave the decision making in the hands of the project manager; }\end{array}$ \\
\hline Identify core competencies & $\begin{array}{l}\text { - To integrate SWOT analysis with partner selection; } \\
\text { - To include expert judgment in partner selection; }\end{array}$ \\
\hline Schedule planning & $\begin{array}{l}\text { - To create schedule with work package description (Level } 3 \text { work breakdown structure) and allow the } \\
\text { team to define the Level } 4 \text { work breakdown structure; } \\
\text { - To sequence work within each phase; }\end{array}$ \\
\hline Risk planning & - To evaluate risks at every step of the way from project initiation; \\
\hline \multirow[t]{4}{*}{ Others } & $\begin{array}{l}\text { - To create an issue management activity in Module } 2 \text { to manage possible issue and prevent them from } \\
\text { becoming risks; }\end{array}$ \\
\hline & - To separate the Expert review from phase gate review; \\
\hline & - To identify key persons in the initiation of each task in each module; \\
\hline & - To automate the PMM guidebook as a web enabled application; \\
\hline
\end{tabular}

Table 5. Observations and comments from the pilot PMM evaluation.

\begin{tabular}{|c|c|}
\hline Criteria & Observations and comments by respondents \\
\hline Feasibility & $\begin{array}{l}\text { - It is a comprehensive approach (U1, U3, U5); } \\
\text { - It is clear and concise, not too complex with good examples, hints and tips (U1, U8); } \\
\text { - It sets things in a structured step by step for project manager so each project could be managed in the same way (U5, U6); } \\
\text { - It includes too many activities therefore some specialization may be useful (U6); } \\
\text { - It could be very time consuming and expensive (U6, U8, PME2); } \\
\text { - Every organization could benefit from this discipline while research group would required more tailoring and flexibility } \\
\text { (PME2); }\end{array}$ \\
\hline Usability & $\begin{array}{l}\text { - It seems a bit more complicated than industrial practices especially end-user environment (U3); } \\
\text { - It is simple to follow and identical to current company practices (PME1); } \\
\text { - Navigation in the online version would be useful (U1, U3, U4, U6); } \\
\text { - Useful to encourage industry participation as this gives them more visibility into the progress of the project, opportunities } \\
\text { for communication and to evaluate the outcome (U1); } \\
\text { - More specificity (U5); } \\
\text { - It is easy to fill in but not with the correct input (U6); } \\
\text { - Adequate for basic research in management which can be a great help for researchers (U8); } \\
\text { - For business managers who need guidance in managing collaborative project for the first time (PME1); }\end{array}$ \\
\hline Usefulness & $\begin{array}{l}\text { - Good layout, user friendliness, easy to follow, detailed definitions and information, clearly articulated (U8, PME1, PME2); } \\
\text { - Its simplicity and ease of use should be highlighted to encourage skeptics (U1); } \\
\text { - It is very comprehensive and includes all the techniques and theory developed by various authors (U6); }\end{array}$ \\
\hline
\end{tabular}

Notes: University (U); Project Management Expert (PME). 
Overall, the pilot evaluation of the PMM supported the feasibility; usability and usefulness of the methodology. The evaluation also indicated a need to test the PMM in the next phase of this study in order to further validate its level of maturity and capability. Suggested changes and comments observed from the evaluation were used to refine the PMM, the final version of the PMM is presented in the next section.

\subsection{Phase 4: final PMM version}

The methodology presented in this section is the final outcome from the literature reviewed, interviews conducted and evaluated as described above. The PMM has been developed based upon a review of leading project management best practices (CHIN et al., 2010) and organization sector specific methodologies available in the market (CHIN; SPOWAGE, 2010). It was designed as a guidebook aimed to provide a systematic approach to assist and support in the planning and management of UIC research projects. It is hoped that this guidebook will assist those involved in undertaking a UIC research projects for the first time and also for those who are continuing an existing research. It is also intended for research management office (or equivalent) of universities and companies to use this guidebook to design their own organization specific PMM to help them work more effectively in UIC research projects.

The basic structure of the PMM is divided into 4 modules based on project management processes group; initiating, planning, executing, controlling and closing of project with selected toolkits and templates for implementation (see Figure 2). The guidebook contains easy step by step guides, provides the objective, 19 activities, inputs, outputs and toolkits (see Table 6 to 9) in each module, as well as containing 34 sets of toolkits enclosed with samples of simplified designed templates, hints and tips to guide first time UIC researchers. This guidebook does not answer all questions but facilitates university and industrial players to customize the available approaches, tools and templates to fit to different project sizes, complexity, objectives and requirements.

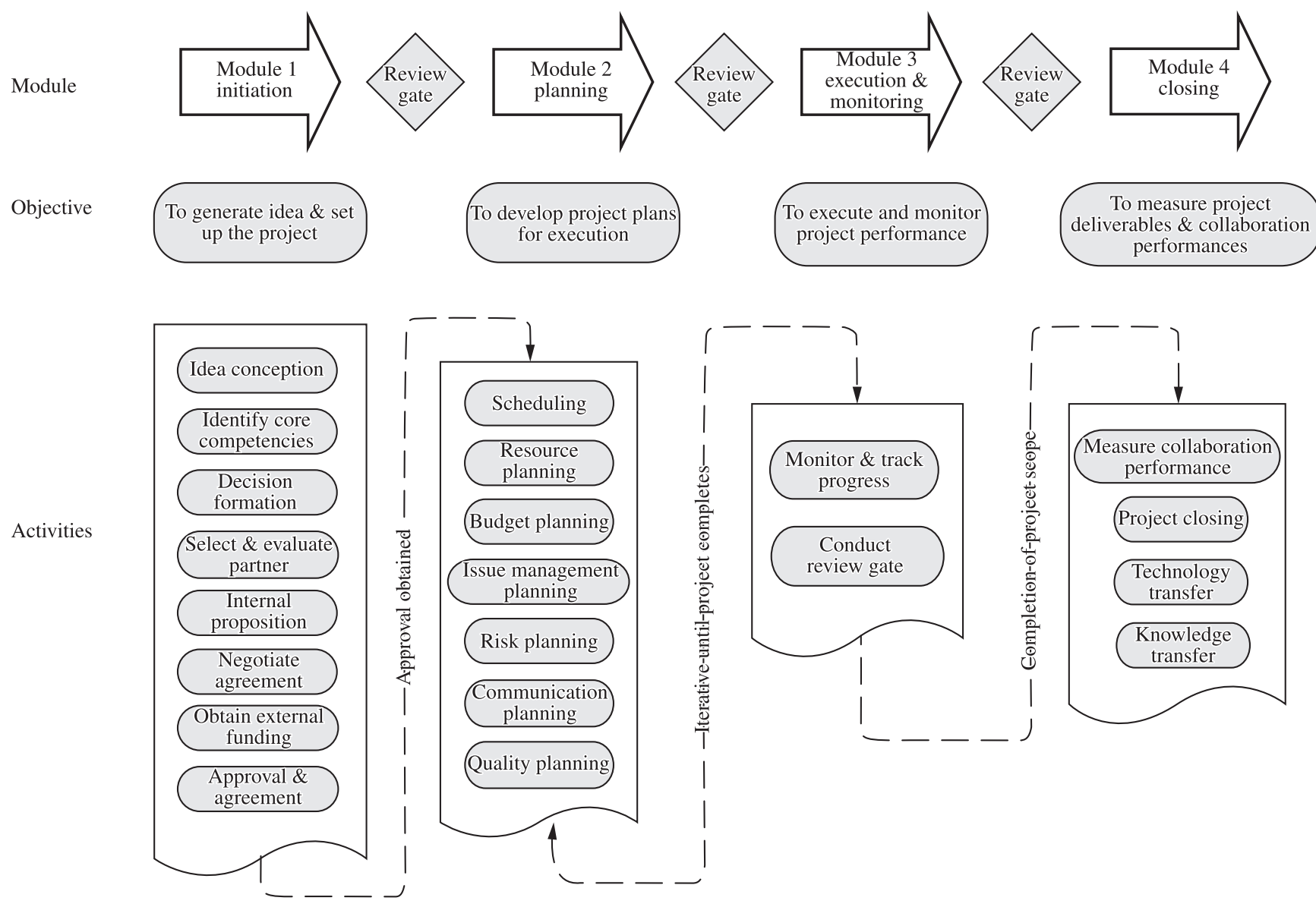

Activities excluded in the PMM guidebook

Figure 2. Final PMM high level framework. 
Table 6. PMM Module 1 Initiation.

\begin{tabular}{|c|c|}
\hline Description & $\begin{array}{l}\text { The objective of this phase is to generate potential idea and set up the project. The activities involved writing up a project } \\
\text { proposal, selecting and evaluating potential partners, developing a project initiation document and signing of the contractual } \\
\text { agreement. }\end{array}$ \\
\hline Key objectives & $\begin{array}{l}\text { - To identify a unique purpose of the project; } \\
\text { - To define project objectives, goals and mission; } \\
\text { - To identify potential collaborative partners; } \\
\text { - To develop a project initiation document; } \\
\text { - To write up an agreement and obtain approval to initiate the project planning module; }\end{array}$ \\
\hline Key activities & $\begin{array}{l}\text { - Develop a project proposal to set the objectives and purpose; } \\
\text { - Collaborative partners are assessed based on a list of criteria; } \\
\text { - A project initiation document (PID) is produced which provides a high level plan of the project, a description of the } \\
\text { project, objectives, scope of work, deliverables, approaches, and constraints; } \\
\text { - Project manager and team members need to be recruited and a project organization structure is created. Project } \\
\text { stakeholders are identified and roles and responsibilities are assigned; } \\
\text { - A kick off meeting between partners is held to clarify the project scope, requirements and expectations from each } \\
\text { partner for example schedule, budget, quality, roles and responsibilities, reporting plan and etc. This also strengthens } \\
\text { communications channels; } \\
\text { - A contractual agreement is write up and agreed; }\end{array}$ \\
\hline Key outputs & $\begin{array}{l}\text { - Project proposal; } \\
\text { - Project initiation document (PID); } \\
\text { - Stakeholder analysis and project team; } \\
\text { - Selected collaborative partner; } \\
\text { - Contractual agreement. }\end{array}$ \\
\hline
\end{tabular}

Table 7. PMM Module 2 Planning.

\begin{tabular}{|c|c|}
\hline Description & $\begin{array}{l}\text { The output from Module } 1 \text { will contribute as input to this module. This module is the main component of PMM and } \\
\text { covers project planning such as schedule, budget, resources, issue management, risk, communication and quality planning. }\end{array}$ \\
\hline Key objectives & $\begin{array}{l}\text { - To develop an activity schedule; } \\
\text { - To identify project resources and budget; } \\
\text { - To document and track issues arising in the project; } \\
\text { - To identify, plan and response to risk and uncertainties in the project; } \\
\text { - To plan the communication and information distribution channel; } \\
\text { - To identify and assure quality target meets stakeholders expectations; }\end{array}$ \\
\hline Key activities & $\begin{array}{l}\text { - Break down project activities into manageable work packages; } \\
\text { - Sequence and schedule all activities using a Gantt chart; } \\
\text { - Create a resource plan and estimate budget for procurement; } \\
\text { - Create an issue management plan to document identified issues in the project; } \\
\text { - Create a risk plan to mitigate and control risks in the project; } \\
\text { - Create a communication plan to identify who, what and how to distribute information throughout project life cycle; } \\
\text { - Create a quality plan to identify acceptable criteria and standards; }\end{array}$ \\
\hline Key outputs & $\begin{array}{l}\text { - Work breakdown structure (WBS) and WBS dictionary; } \\
\text { - Project schedule (Gantt chart); } \\
\text { - Resource plan; } \\
\text { - Budgetary plan (baseline); } \\
\text { - Issue management plan; } \\
\text { - Risk plan and risk log; } \\
\text { - Communication plan; } \\
\text { - Quality plan and quality log. }\end{array}$ \\
\hline
\end{tabular}

\subsection{Phase 5: validating the final PMM version}

The aim of this validation is to test the final PMM guidebook as to determine whether the methodology is generic and practical for use in a much wider application and implementation. To enable a valid evaluation, the final PMM guidebook and the questionnaire survey were re-sent to the same group of expert review panel who had evaluated the pilot PMM as discussed Phase 2.

Based on the evaluation of the methodology's feasibility, all respondents agreed that the finalized PMM guidebook was easy to follow as it is comprehensively adequate to be 
Table 8. PMM Module 3 Execution \& monitoring.

\begin{tabular}{|c|c|}
\hline Description & $\begin{array}{l}\text { Completion of project planning documents and approval from stakeholders will initiate the execution and development } \\
\text { of the project. This module is critical because the project manager needs to constantly control and monitor project } \\
\text { performances to ensure it meets the expectations of all stakeholders. The monitoring process begins when the project } \\
\text { starts and continues until it ends. }\end{array}$ \\
\hline Key objectives & $\begin{array}{l}\text { - To ensure each project objective is delivered as planned; } \\
\text { - To coordinate the completion of all tasks within schedule and budget; } \\
\text { - To monitor change requests and minimize impact on project scope, schedule and budget; } \\
\text { - To keep track of project progress against plans through performance reporting; } \\
\text { - Take corrective action against changes as recommended by collaboration agents committee; }\end{array}$ \\
\hline Key activities & $\begin{array}{l}\text { - Conduct meetings to monitor and track project progress; } \\
\text { - Document project performance through minutes, progress report, and progress log; } \\
\text { - Document change requests and monitor execution in the change of plan; } \\
\text { - Perform activity review gate at the completion of each activity in a module; } \\
\text { - Perform module review gate at the completion of each module; } \\
\text { - To iterative the above activities until all project objectives are delivered; }\end{array}$ \\
\hline Key outputs & $\begin{array}{l}\text { - Project minutes; } \\
\text { - Project progress report; } \\
\text { - Progress log checklist; } \\
\text { - Change request plan and request log. }\end{array}$ \\
\hline
\end{tabular}

Table 9. PMM Module 4 Closing.

\begin{tabular}{|c|c|}
\hline Description & $\begin{array}{l}\text { Finally the collaboration comes to an end. The closing module includes measuring the deliverables of a collaborative } \\
\text { project, documenting lesson learned and project archives, and official acceptance sign off and handover of final product } \\
\text { to stakeholders. This module is also an important determination of whether the collaborative can be sustained for future } \\
\text { partnership. }\end{array}$ \\
\hline Key objectives & $\begin{array}{l}\text { - To identify and measure collaborative performance; } \\
\text { - To document lesson learned from project experience; } \\
\text { - To gain acceptance of the completion of all project work; } \\
\text { - To signoff and handover to stakeholders to close the project; } \\
\text { - To sustain relationship for future partnership; }\end{array}$ \\
\hline Key activities & $\begin{array}{l}\text { - To measure the collaborative performance indicators in terms of four perspectives; financial, customer, internal } \\
\text { processes and learning and innovation growth; } \\
\text { - To create lesson learned report for future project reference; } \\
\text { - To update and archive all scope of work completed and variances of project performances in the end project report; } \\
\text { - Prepare formal acceptance for signoff and handover of project; }\end{array}$ \\
\hline Key outputs & $\begin{array}{l}\text { - Collaborative performance measurement indicators; } \\
\text { - Lesson learned report; } \\
\text { - End project report; } \\
\text { - Signoff and handover of project. }\end{array}$ \\
\hline
\end{tabular}

communicated in between team members in a project based research environment. In addition, the final PMM guidebook is appropriate as it has included all the necessary activities for use for better managing a collaborative research project environment. The majority agreed that the methodology should be put forward for adoption in their research group or organization with appropriate customization. The PMM guidebook had also been successfully adopted by an academician (U4) to manage his project. The designed toolkit was adopted by his project team for documentation, execution, monitoring and controlling of the project.

On the PMM guidebook's usability, the final results from all respondents showed that the methodology is usable for individualized project or to supplement existing practices and method in an organization. The supporting reasons that majority of the respondents agreed to, was the methodology has included the relevant toolkits and templates which are easy to use, modifiable and customizable in a collaborative research environment. Lastly, on the aspect of usefulness, the majority of respondents indicated their support and consideration in utilizing the methodology for their collaborative project as they unanimously was satisfied with the structure, design and contents of the methodology. Overall, the final evaluation and validation of the PMM guidebook received positive recognition and feedback on its feasibility and usefulness for adoption and application in a UIC research environment. This evaluation had also significantly indicated that the next phase of this study could be put forward in a real UIC case project with certainty. 


\section{Conclusion}

The above discussion can be used to extract the components which constitute and the requirements placed on an effective PMM. In this work, a PMM governs the management of projects through the use of an appropriate method according to prescribed practices within a particular project environment. The PMM is concerned with the planning and coordination of projects from conceptualization to closing to meet the requirements of stakeholders within the given budget and timeline. It must be consistent with the standards, rules, regulations and the best practices relevant to the project environment. A PMM should be customizable to allow it to meet the requirements of every project within the environment regardless of nature or size. The methodology must be compatible with the organization's existing management systems and able to integrate established project management tools which may be currently in use or imposed by external parties such as governmental funding agencies. By using an appropriate methodology, a project manager is able to identify and minimize risks, satisfy stakeholders' expectations and internalize learning from the process. Therefore, the objective of this research is to design a dynamic, flexible and adaptive PMM which should be viable and scalable to suit any project within the UIC research environment.

Worldwide companies have strongly voiced their difficulties in matching their practical approaches with academicians theoretical view (WU, 2000) especially in relation to the way projects are managed. While academic researchers lack the skills in managing and planning research project (GIST; LANGLEY, 2007) they possess a depth of expertise which is hard to find in modern corporations. On the other hand, industrial players lack understanding or appreciation of the research process. Therefore, this research aims to make a significant contribution to the theory and practice of UIC project management in Malaysia by developing a systematic PMM to bridge the gap between industrial and academic perspectives so partnership can be strengthened. Further, this research also contributes to the body of knowledge of UICs in Malaysia which presently has received very little academic attention. It further explored the work of YEE et al. focusing on the aspects of project management for UIC that were not explored in their research (YEE; CHONG; ABAS, 2009b). It also contributes to the policy and practices of Malaysian UIC partnerships in the aspects of project management knowledge and applications that have yet to be investigated.

In addition, studies by other authors have indicated the level of interaction and collaboration between UIC in Malaysia is still very limited which significantly impedes collaboration potential (ALI, 2003; ABDUL RAZAK, 2010; ZAKARIAH; YEOP MAJLIS; RAHMAN, 2004;
MALAIRAJA; ZAWDIE, 2008). With a number of initiatives taken by the government in recent years there is now more intense effort and focus to cultivate a UIC culture. This research provides a dyadic view of the best practices and lesson learned from previous and existing UICs which contributed to the conceptualization of the PMM.

\section{References}

ABDUL RAZAK, D. Research alliance with industry: USM's perspective. Universiti Sains Malaysia, 2010.

ADESOLA, S.; BAINES, T. Developing and evaluating a methodology for business process improvement. Business Process Management Journal, v. 11, p. 37-46, 2005. http:// dx.doi.org/10.1108/14637150510578719

ALI, A. Engaging economic development through the commercialisation of research: The Malaysian experience. In: ASSOCIATION OF COMMON WEALTH UNIVERSITIES - ACU CONFERENCE, 2003, Belfast. Proceedings... ACU, 2003.

ASLAN, A. S. University-industryre search \& technological links in Malaysia. Faculty of Humanities, University of Manchester, 2006.

AUGUSTINE, M. S.; COOPER, C. D. Getting the Most from Strategic Partnering: A Tale of Two Alliances. Organizational Dynamics, v. 38, p. 37-51, 2009. http:// dx.doi.org/10.1016/j.orgdyn.2008.10.006

BUTLER, R.; GILL, J. Knowledge and trust in partnership formation. In: GENEFKE, J.; McDONALD, F. (Eds.). Effective Colllaboration Managing the Obtacles to Success. Palgrave, 2001.

CHARVAT, J. Project management methodologies: selecting, implementing and supporting methodologies and processes for projects. John Wiley \& Sons, 2003.

CHEMMA, A.; SHAHID, A. A. Customizing Project Management Methodology. In: INTERNATIONAL MULTITOPIC CONFERENCE, 9., 2005, Karachi. Proccedings... IEEE INMIC, 2005.

CHIN, C. M. M.; SPOWAGE, A. C. Project management methodology requirements for use in undergraduate engineering research projects. In: IEEE INTERNATIONAL CONFERENCE ON MANAGEMENT OF INNOVATION \& TECHNOLOGY, 4., 2008, Bangkok. Proceedings... Bangkok: IEEE, 2008.

CHIN, C. M. M.; SPOWAGE, A. C. Defining \& classifying project management methodologies. PM World Today, v.12, n. 5, 2010.

CHIN, C. M. M. et al. Developing a project management methodology for use in doctoral research project. Journal of Institutional Research of South East Asia, v. 9, 2011. 
CHIN, C. M. M.; YAP, E. H.; SPOWAGE, A. C. Reviewing Leading Project Management Practices. P M World Today, v. $12,2010$.

COCKBURN, A. A methodology per project. Humans \& Technology Technical Report, 1999.

COCKBURN, A. Just in time methodologyconstruction. Human \& Technology Technical Report, 2000.

COCKBURN, A. The End of Software Engineering and the Start of Economic-Cooperative Gaming. Computer Science and Information Systems, v. 1, p. 1-32, 2004. http://dx.doi. org/10.2298/CSIS0401001C

COOMBS, R.; McMEEKIN, A.; PYBUS, R. Toward the development of benchmarking tools for R\&D project management. R\&D Management, v. 28, 1998.

DAVENPORT, S., DAVIES, J.; GRIMES, C. Collaborative research programmes: building trust from difference. Technovation, v. 19, p. 31-40, 1999. http://dx.doi. org/10.1016/S0166-4972(98)00083-2

ERNO-KJOLHEDE, E. Project management theory and the management of research projects. Copenhagen: Copenhagen Business School, 2000.

EVALSED. Source books: Method and techniques. Regional Policy - Inforegio, 2009.

GIST, P.; LANGLEY, D. Application of standard project management tools to research a case study from a multinational clinical trial. Journal of Research Administration, v. 38 , n. $2,2007$.

GUO, G.; CHEN, Y.; ZHOU, X. R\&D project management standardization: na empirical research. In: INTERNATIONAL CONFERENCE OF ELECTRICAL ENGINEERING MANAGEMENT, 2007, Coimbra. Proceedings... IEEE, 2007.

HARRIS, T. Collaborative research \& development project - a practical guide. Springer-Verlag, 2007.

HOLMBERG, S. R.; CUMMINGS, J. L. Building Success ful Strategic Alliances: Strategic Process and Analytical Tool for Selecting Partner Industries and Firms. Long Range Planning, v. 42, p. 164-193, 2009. http://dx.doi. org/10.1016/j.lrp.2009.01.004

HULJENIC, D; DESIC, S.; MATJASEVIC, M. Project management in research projects. In: INTERNATIONAL CONFERENCE ON TELECOMMUNICATIONSConTEL, 2005, Zagreb. Proceedings... Zagreb, Croatia, 2005.

JOSLER, C.; BURGER, J. Project Management Methodology in HRM. Cupa HR Journal, v. 56, p. 25-30, 2005.

KANTER, R. M. Collaborative advantage. Harvard Business Review, 1994.
KATZ, J. S.; MARTIN, B. R. What is research collaboration? Research Policy, v. 26, p. 1-18, 1997. http://dx.doi. org/10.1016/S0048-7333(96)00917-1

KAUTZ, K.; PRIES-HEJE, J. System development education and methodology adoption. ACM SIGCPR Computer Personnel, v.20, p. 6-26, 1999. http://dx.doi. org/10.1145/568508.568509

KOECH, J. K. A casestudy of university-industry partnership. Canada: University of Alberta, 1995.

LLYOD, S.; SIMPSON, A. Project management in multidisciplinary collaborative research. In: INTERNATIONAL P R O F E S S I O N A L C O M M U N I C A T I O N CONFERENCE - IPCC, 2005, Limerick, Ireland. Proceedings... IEEE, 2005.

MALAIRAJA, C.; ZAWDIE, G. Science parks and universityindustry collaboration in Malaysia. Technology Analysis \& Strategic Management, v. 20, p. 727-739, 2008. http:// dx.doi.org/10.1080/09537320802426432

MATTHEW, J. N.; NORGAARD, R. Managing the partnership between higher education and industry. Colorado:National Center for HigherEducation Management Systems, 1984.

MILOSEVIC, D.; PATANAKUL, P. Standardized project management may increase development Project success. International Journal of Project Management, v. 23, p. 181-192, 2005. http://dx.doi.org/10.1016/j. ijproman.2004.11.002

MORRISON, G. R.; KEMP, J. E.;ROSS, S. M. The Many Faces of Evaluation. In: MORRISON, G. R.; KEMP, J. E.; ROSS, S. M. Designing Effective Instruction. New York: John Wiley \& Sons, 2001.

MULDER, L. The importance of a common project management method in the corporate environment. R\&D Management, v. 27, 1997.

MUNNS, A. K.; BJERMI, B. F. The role of project management in achieving Project success. International Journal of Project Management, v. 14, p. 81-87, 1996. http://dx.doi. org/10.1016/0263-7863(95)00057-7

MURCH, R. Project management Best practices for IT professional. Prentice Hall, 2001.

PHILBIN, S. Process model for university-industry research collaboration. European Journal of Innovation Management, v. 11, p. 488-521, 2008. http://dx.doi. org/10.1108/14601060810911138

PITAGORSKY, G. The business value of embracing a unifiedpm methodology. Allpm.com, 2003.

PLATTS, K. W. Manufacturing audit in the process of strategy formulation. Cambridge: University of Cambridge, 1990. 
PROJECT MANAGEMENT FACT SHEET. Why Project Management. Tasmania Government, 2004.

REGO, L. M.; CARVALHO, L. C. Managing R\&D projects: a systemic approach. In: ENGINEERING MANAGEMENT CONFERENCE, 1995. Proceedings... IEEE, 1995.

SCRIVEN, M. Types of evaluation and types of evaluator. Evaluation Practice, v. 17, p. 151-161, 1996. http://dx.doi. org/10.1016/S0886-1633(96)90020-3

SHENHAR, A. J. Strategic project management: the new framework. In: MANAGEMENT OF ENGINEERING TECHNOLOGY, TECHNOLOGY \& INNOVATION MANAGEMENT INTERNATIONAL CONFERENCE, 1999, Portland. Proceedings... Portland, 1999.

SHERWOOD, A. L.; BUTTS, S. B.; KACAR, S. L. Patnering for knowledge: a learning framework for universityindustry collaboration. In: MIDWEST ACADEMY OF MANAGEMENT CONFERENCE, 2004, Minneapolis. Proceedings... MidwestAcademy of Management,2004.

TIMES HIGHER EDUCATION - THE. QS World University Rankings 2009. Times Higher Education, 2009.

TURBIT, N. Project Management \& Software Development Methodology. Tech Republic, 2005. (The PROJECT PERFECT White Paper Collection). van TIEM, D. M.; MOSELEY, J. L.; DESSINGER, J. C. Fundamentals of performance technology: A guide to improving people, processand performance. Washington, International Society for Performance Improvement, 2004.

WECK, M. Knowlege creation and exploitation in collaborative R\&D project: lesson learned on success factors. Knowledge \& Process Management, v. 13, p. 252-263, 2006. http:// dx.doi.org/10.1002/kpm.261

WU, F. S. Anempirical study of university-industryre search cooperation-The case of Taiwan. Rome: OECD-NIS Fosu Groupon Innovation Firmand Networks, 2000.

YEE, S. V.; CHONG, A. L.; ABAS, Z. Strategic collaborative success factors and sustainability indicators of academia industry collaboration: case studies of two universities in Malaysia. Journal of the World Universities Forum, v. 2, 2009a.

YEE, S. V.; CHONG, A. L.; ABAS, Z. University-Industry collaboration comparativ estrategic collaborative management practice. Ministry of Higher Education, $2009 \mathrm{~b}$. Final report.

ZAKARIAH, Z. A.; YEOP MAJLIS, B.; RAHMAN, S. University-industry partnership in micro engineering and nanoelectrical in Malaysia. Kuala Lumpur: IEEE, 2004. 
Appendix 1. Interview question.

Describe the processes involved in establishing collaboration?

Why collaboration?

What key elements are needed in the planning process?

What structures are created/adopted to coordinate the collaboration?

Who are the key people involved in the project management? (Is there a project manager from each partner?)

Do you/institution adopt a PMM to manage the collaboration? If yes/no why?

If there is a PMM, what should be included in it?

How collaboration progress is monitored and controlled?

What are the problems that may occur in the collaboration?

What are the best practices/success element to better manage collaboration?

How the collaboration performance is measured?

What are the sustainability criteria for UIC growth in Malaysia?

University researchers should be equipped with industrial experiences. What is your view?

Do you think project management skill is a contributing element to collaboration success? Why?

Appendix 2. Evaluation questions.

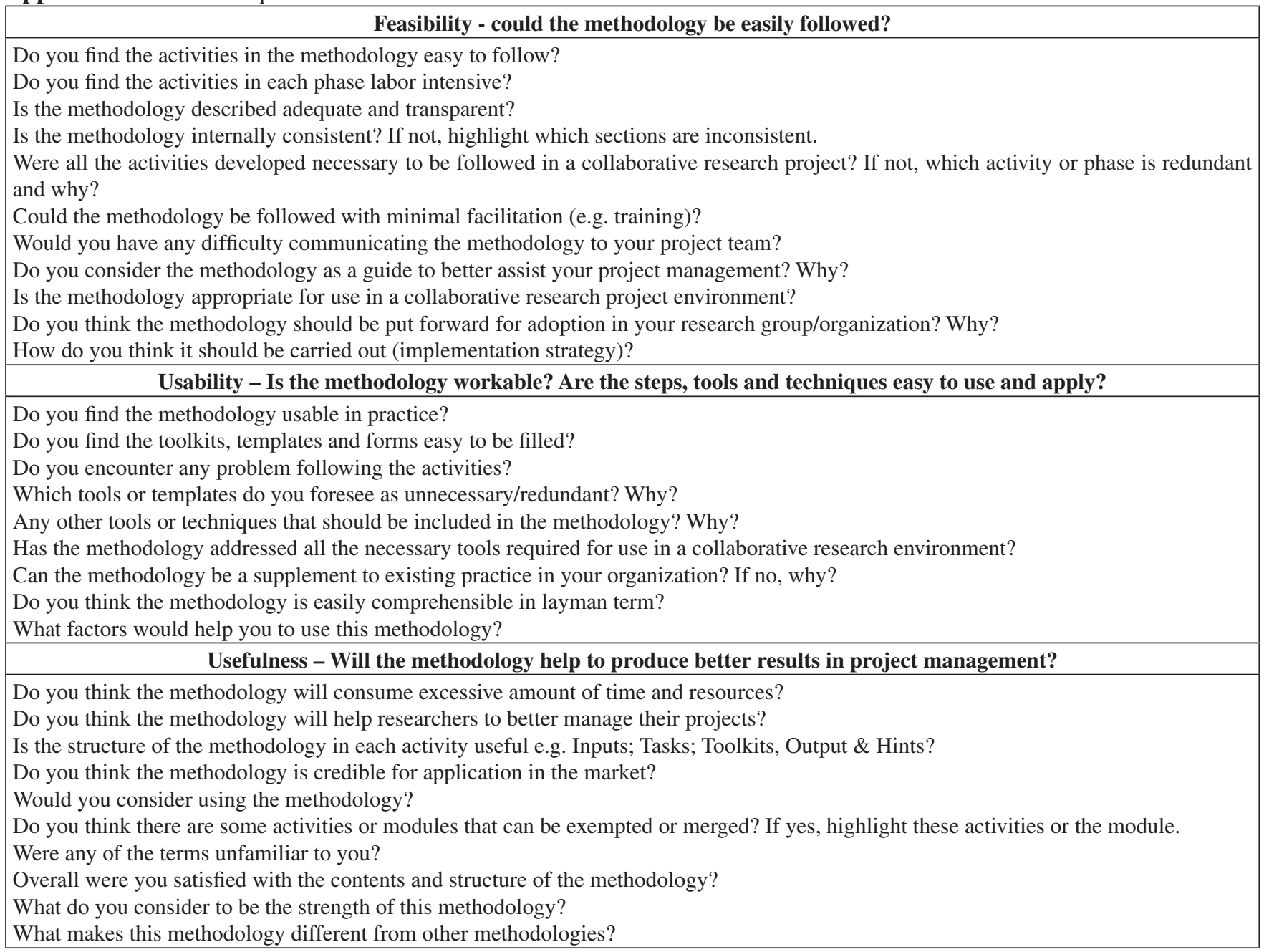


